\title{
Effects of late miticide treatments on foraging and colony productivity of European honey bees (Apis mellifera)
}

\author{
Théotime Colin $^{1,2}$ (D) Casey C. Forster ${ }^{1}$, Jack Westacott ${ }^{1}$, Xiaobo Wu ${ }^{3}$, \\ William G. MEIKLE ${ }^{4}$, Andrew B. BARRON ${ }^{1}$ \\ ${ }^{1}$ Department of Biological Sciences, Macquarie University, Sydney, NSW, Australia \\ ${ }^{2}$ School of Life and Environmental Sciences, The University of Sydney, Sydney, NSW, Australia \\ ${ }^{3}$ Honeybee Research Institute, Jiangxi Agricultural University, Nanchang, Jiangxi, China \\ ${ }^{4}$ Carl Hayden Bee Research Center, USDA-ARS, Tucson, AZ, USA
}

Received 17 April 2020 - Revised 4 October 2020 - Accepted 16 December 2020

\begin{abstract}
Chemical miticides are used routinely in honey bee colonies worldwide as treatment for the parasitic mite Varroa destructor, but there have been very few long-term colony-level field studies of the impacts of miticides on the bees themselves. Lab-based studies with individual bees or bees in small groups have highlighted many negative effects of miticides on bee behaviour and physiology; hence, there is an urgent need to better understand the consequences of miticides on honey bee colonies in an apicultural setting. Here we compared effects of commercial treatments of the miticides tau-fluvalinate and thymol, and controls, on honey bee colonies and bee foraging behaviour over five months, from autumn through winter in Sydney, Australia. Since V. destructor does not occur in Sydney, in this study, we could isolate the direct effects of the miticides from indirect effects resulting from reduced mite load. We found the autumn treatment of either miticide caused no significant change in bee adult or brood population or size of food stores. The average temperature in the thymol group differed from the temperature in the control group and was lower during winter. Neither miticide reduced bee longevity. Tau-fluvalinate caused bees to start foraging earlier in life and perform shorter trips, but no other effects on foraging behaviour were documented. To conclude, in Sydney, Australia, limited negative effects of autumn thymol or tau-fluvalinate treatments were observed on bees or bee colony performance.
\end{abstract}

\section{miticides / acaricides / Varroa destructor / RFID / continuous weight measurement}

\section{INTRODUCTION}

Presently, there is a strong focus of research into the impacts of agricultural pesticides on the health of pollinators (Klein et al. 2017; Prado et al. 2019), but far less attention has been given to the effects of pesticides used by beekeepers within their hives on the health and performance of honey bees. The global spread of the parasitic mite Varroa destructor (now found worldwide, with the exception of Australia and a few small islands

Corresponding author: T. Colin, theotime.colin@gmail.com

Manuscript Editor: Peter Rosenkranz
(De Jong et al. 1982; Rosenkranz et al. 2010)), has led to various miticides being the most common pesticides found within hives (Mullin et al. 2010). A 2010 survey reported that 5 out of the 10 most abundant pesticides in the wax from North American hives were miticides. Two of these miticides, fluvalinate and coumaphos, were present in over $98 \%$ of the samples, and a third, amitraz, was found in over $60 \%$ of the samples (Mullin et al. 2010).

Some miticides are known to have negative effects on bees (Tihelka 2018, see below for a brief overview). Their residues can accumulate in the wax and the honey stores for up to several months, which increases the risks of chronic 
exposure, and potential for synergistic effects with other pesticides (Johnson et al. 2013; Mullin et al. 2010; Tihelka 2018; Prado et al. 2019).

Current data from surveys and pesticides analyses highlight the diversity of miticides used and suggest that amitraz, tau-fluvalinate, coumaphos, flumethrin, thymol, oxalic acid and formic acid are the most commonly used miticides (Mullin et al. 2010, Brodschneider et al. 2019). Other chemicals and mixtures are sometimes reported among amateur beekeepers, as well as diverse methods or timing of application for the same chemical (Tihelka 2018; Beyer et al. 2018; Brodschneider et al. 2019; Underwood et al. 2019).

A number of studies examining individuals or groups of honey bees isolated in the laboratory suggest that commercially available miticide treatments could have negative effects on bees (extensively reviewed in Tihelka 2018). Briefly, tau-fluvalinate affects individual survival (Berry et al. 2013; Haarmann et al. 2002), reproduction (Haarmann et al. 2002) and olfactory memory (Frost et al. 2013) and interacts with the neonicotinoid imidacloprid to affect learning (Colin et al. 2020). Thymol affects hygienic behaviours (Colin et al. 2019a), olfactory memory and phototactic response (Carayon et al. 2014; Alayrangues et al. 2016; Bonnafé et al. 2017). Amitraz affects the expression of some proteins (Gregorc et al. 2012). Coumaphos affects the expression of detoxification genes (Boncristiani et al. 2012), and the reproduction of bees (Burley et al. 2008; Haarmann et al. 2002; Pettis et al. 2004). Formic acid increases egg mortality to about $80 \%$ (Giusti et al. 2017). Oxalic acid increases both adult bee mortality (Coffey and Breen 2016) and brood mortality (Hatjina and Haristos 2005; Toomemaa et al. 2010).

Little is known about whether these effects on individual and groups of bees have consequences at the colony-level. Only two long-term colonylevel studies of the effects of miticides have been conducted to date. These both focused on interactions between a single miticide and neonicotinoid crop insecticides (Colin et al. 2019b; Odemer and Rosenkranz 2020) and thus far there are no comparative colony-level studies on the effects of different miticides. In one study, the miticide thymol was applied as a summer treatment in two locations: in Sydney, Australia, where $V$. destructor is absent and in Tucson, USA, where the mite was present (but only at very small populations within hives: 1.17 to 3.38 mite fall per day on average in the control group, see Colin et al. 2019b). The summer thymol treatment was found to affect the number of brood cells, the number of bees and the mass of honey stores during treatment and in the first month following the treatment in Sydney compared to the control. Thymol had less of an impact on bees in Tucson (Colin et al. 2019b).

In Odemer and Rosenkranz (2020), taufluvalinate was applied as a chronic treatment during both summer and winter in colonies located in Germany, where $V$. destructor is considered a major pest by beekeepers (Odemer and Rosenkranz 2020). In two successive years, colonies treated with tau-fluvalinate did not have significantly different amounts of brood cells or bees than control colonies. Tau-fluvalinate treated colonies experienced fewer overwintering losses than controls, but due to the small number of colonies involved in the experiment this could not be tested statistically (Odemer and Rosenkranz 2020).

These first colony-level studies provide a pessimistic outlook on whether miticides have any positive impact on the performance of honey bee colonies. It has been hypothesised that the lack of clear beneficial effects of these miticide at the colony level, despite significant effects on $V$. destructor populations, could result from potential negative effects of these miticides on the bees themselves (Colin et al. 2019b). Interestingly, the effects of miticides on the overwintering success of honey bee colonies have been suggested to strongly depend on the season during which the treatment is applied. Thymol treatments have been correlated with decreased overwinter losses when applied in summer, but with 
increased losses when applied in autumn (Beyer et al. 2018). Beekeepers, however, are likely to prefer applying miticide treatments in autumn to tackle $V$. destructor populations before winter, and also to avoid contaminating late season honey harvests with miticide residues.

To address the relative lack of colony-level studies of the impacts of miticides on honey bees, here we measured the effects of thymol and taufluvalinate as early-autumn treatments on the population and food stores of bee colonies in the field. In addition, we sampled newly emerged bees from hives treated with these miticides and controls and measured their individual foraging performances and survival using RFID tags. Assessing these effects at a location where $V$. destructor is absent allows us to compare treatment and control groups without the effects of increased $V$. destructor load in control colonies confounding the results.

\section{MATERIAL AND METHODS}

\subsection{Hives and context}

On the 27th of November 2017 (spring in Australia), 25 hives were established on the campus of Macquarie University (33 $33^{\circ} 46^{\prime} 06.6^{\prime \prime} \mathrm{S}$ $151^{\circ} 06^{\prime} 43.8^{\prime \prime}$ E, Macquarie Park, NSW, Australia). Colonies were established from bee packages containing $1.5 \mathrm{~kg}$ of bees sourced from the Macquarie University research apiary. Colonies contained "Golden Italian" queens (a common commercial strain in Australia: Australian Queen Bee Exporters Pty. Ltd. Blayney, NSW), and were housed in standard wooden "deep Langstroth" 8frames hives of a volume of about $35.5 \mathrm{~L}$ with Australian "migratory" lids (equipped with vents that were shut during treatment). In starting condition, colonies were given four frames of printed wax comb and a frame feeder. Colonies were fed with $6 \mathrm{~L}$ of syrup and $1 \mathrm{~kg}$ of pollen patty during the first month after establishment, after which no more food was given. Pollen patty was composed of pollen, sucrose, glucose, fructose, water in the ratios 1:1:0.75:0.75:1. Pollen was obtained as honeybee "feedback" pollen pellets from Hornsby Beekeeping Supplies (Hornsby, NSW). The frame feeder was then removed and an additional 4 frames with printed wax comb were added to each hives.

On the 15th of March 2018, we selected 21 healthy colonies from the 25 colonies previously established for the experiment. Prior to the experiment one colony absconded, two other colonies were not included due to early queen losses, one colony had less than 500 workers. After the beginning of the experiments, one of these colonies suffered damage from a storm and was excluded from the experiment on the 12th of April 2018 (sample sizes given below already exclude this hive). A top box was added on October 2018, a year after the beginning of the experiments.

It should be noted that Varroa destructor and predatory hornets have not yet been detected in Australia. American Foul Brood can occur but was not detected in our colonies. Wax moths, chalk brood and hive beetles were present opportunistically, and hives were equipped with APITHOR traps (Ensystex Pty Ltd, Auburn, NSW, Australia) to prevent hive beetle outbreaks.

\subsection{Treatments}

Treatments were applied from the 10th of April 2018. In Australia, this corresponds to the beginning of autumn and this treatment would match a post-harvest autumn treatment in most countries of the Northern hemisphere (Beyer et al. 2018). Hives were randomly assigned to three treatment groups. Seven hives were assigned to a tau-fluvalinate treatment group, seven to a thymol treatment group and six to a control group (initially seven: one hive was removed following storm damage). The position of the hives was randomised across the apiary. Nine other hives were present in the apiary but located at least $10 \mathrm{~m}$ apart from the hives in this experiment.

Colonies assigned to the tau-fluvalinate group were treated using Apistan ${ }^{\circledR}$ strips containing $10.3 \%$ of tau-fluvalinate (weight to weight, 
824 mg per strip, Vita Europe Ltd., Basingstoke, UK). As per manufacturer's instructions, two Apistan ${ }^{\circledR}$ plastic strips were placed in each colony, between frames 4 and 5 , and frames 5 and 6 where the brood was located. Strips were left in the hives for 6 weeks and were then removed.

Colonies assigned to the thymol group were treated with Apiguard® (Vita Europe Ltd.), which contains $12.5 \mathrm{~g}$ of thymol mixed with $37.5 \mathrm{~g}$ of a slow-release gelatine (2-isopropyl-5-methylphenol) in a small aluminium tray. As per manufacturer's instructions, a single tray was placed on top of the frames of each hive, under the lid. This was left in the hive for two weeks and then replaced with a second tray for a further two weeks.

Residues of tau-fluvalinate can remain in the hive, so bees may have been exposed for a longer period (Tsigouri et al. 2001; Mullin et al. 2010). Apistan strips were dried out when removed. Thymol residues remain in hives, so bees may have been exposed for a longer period (Colin et al. 2019b). Apiguard $®$ thymol trays were donated by Plant Health Australia. Trays were empty by the time they were removed. These standard miticide treatments leave persistent residues in the honey, wax and bees (e.g. Tsigouri et al. 2001; Mullin et al. 2010; Colin et al. 2019c; Meikle et al. 2016a; Martel and Zeggane 2002; Kasiotis et al. 2018; Serra Bonvehí et al. 2016; Adamczyk et al. 2005).

The six control colonies received no treatment.

\subsection{Colony-level measurements}

Each colony was placed on a scale (precision $20 \mathrm{~g}$, maximum capacity $100 \mathrm{~kg}$, TEKFA® model B-2418), each connected to data loggers set to record weight every minute (Hobo® ${ }^{\circledR}-12$, Onset Computer Corporation). This system is given in Meikle et al. (2016b). It provides measures of sufficient precision to estimate daily weight variations, including those resulting from bees leaving their hive in the morning, or water evaporation and respiration at night (Meikle et al. 2018). Only 16 scales were available, consequently 5 of the 21 colonies included in this experiment were not placed on scales (two in the tau-fluvalinate group, one in the thymol group, two in the control group). Two of these hives (one tau-fluvalinate and one control) were weighed manually at night once before each hive evaluation and included in the colony-level measurements. These two hives were permanently moved to the scales after the 20th of August 2018 after colonies placed on scales died. The three remaining hives were only treated to source newly emerged bees for the RFID experiment and no colony-level measurements were taken.

Temperature was measured every $30 \mathrm{~min}$ using temperature loggers (precision $0.0625^{\circ} \mathrm{C}$, iButton Thermochron model DS1922) placed in Australian style plastic queen cages (Hornsby Beekeeping Supplies, Hornsby, NSW, Australia) that were located between the middle frames just above the brood nest.

The amount of bees, capped brood, and capped honey were estimated in comprehensive hive evaluations just before the treatment on the 9th of April 2018, after four weeks of treatment on the 8th of May 2018, and after winter in early spring on the 20th of August 2018. This final measurement was 13 weeks post the end of the treatments. The full protocol for hive evaluations is given in (Meikle and Weiss 2017). In brief, hives were opened and one frame at a time was pulled out of the hive, gently brushed or shaken above the hive to remove bees, photographed and weighed on a precision scale (precision $0.5 \mathrm{~g}$, Ohaus model Ranger Count 3000) and replaced into the hive. This method has greater precision than older methods relying on visual estimates (Colin et al. 2018) and has been used in several ecotoxicological studies (Meikle et al. 2016a; Colin et al. 2019b; Meikle et al. 2019; Meikle et al. 2020; Carroll et al. 2018; Alburaki et al. 2017).

Capped brood areas and capped honey areas were estimated from the frame photographs using CombCount (Colin et al. 2018). Measures were performed by an observer blind to the treatment of each colony (hives were identified by a letter with no information of treatment). Capped brood areas were converted into number of cells and weight using a conversion factor from Meikle et al. (2016b). The weight of the food stores was estimated by subtracting the weight of the empty frame and the estimated weight of the brood from the weight of the whole frame as described in Meikle et al. (2016b) (see Supplementary Material 1). 
Hives were considered dead when there were no more bees inside or when they were too weak to be maintained without risking hive beetle infestations (queenless, with no brood and maximum 200 workers).

\subsection{RFID}

On the 10th of January 2018 one full-size hive was equipped with a modified entrance that separates entering and exiting bees into distinct channels with 93\% minimum daily accuracy (Colin et al. 2019c). The entrance was equipped with four RFID antennae connected to an RFID reader (Invengo XC-RF807) continuously logging data on a Windows computer, see Colin et al. 2019c.

Between the 1st and the 4th of May (during the fourth week of exposure after introducing the treatments on the 10th of April), hives were quickly evaluated to detect pupae about to emerge. Six hives in the control group, six hives in the taufluvalinate group, and five hives in the thymol group had pupae about to emerge, other hives had too little brood about to emerge to be included. One frame of brood from each of these hives was taken and placed in individual metallic boxes with vents covered with mesh on the sides; all boxes were placed together in an incubator overnight $\left(34.5^{\circ} \mathrm{C}, 50 \%\right.$ humidity) for adult bees to emerge. Up to one hundred newly emerged bees were collected from the frames per hive (Supplementary Material 4) and tagged with RFID transponders (Invengo Technology) glued onto their thorax with super glue (Uhu Superglue Carded Ultra-Fast) (see Colin et al. 2019c).

\subsection{Statistical analysis}

Statistical analyses were conducted in R v 3.6.2 (R Core Team 2018).

\subsubsection{Colony performance}

The number of brood cells, bees, and the mass of honey stores were analysed with a repeated measure ANOVA, the value of these parameters at the first evaluation before treatment was added as a fixed effect, the treatment and evaluation number and their interaction were used as fixed effects, hive was a random effect. Pairwise contrasts were generated using "emmeans" v 1.4.5 (Lenth et al. 2018) to obtain comparisons between the control group and the treatment groups for each evaluation following treatment. Dead colonies were removed from the analyses; however, the raw data are available in Supplementary Material 1.

\subsubsection{Daily weight changes}

Piecewise regressions were fit to the daily weight variations of individual hives using a modified version of the method detailed in (Meikle et al. 2018; Holst and Meikle 2018). Briefly, the rolling standard deviation was calculated every three minutes and averaged daily, and a conservative threshold derived from a histogram plot of the daily rolling standard deviation was used to exclude days were measurements were erroneous due to rain or animals interfering with the scale measurements (35 out of 6373 individual data points inferior to $-2.5 \mathrm{~kg}$ of daily weight loss were removed). Inflexion points were detected from loess fits of the daily weight change patterns. The inflexion points closer to sunset and sunrise, and the time at which the mass of the hive was the lowest between these times were used as starting values for the estimation of the breakpoints. Piecewise regressions were then fit using the "segmented" function of the "segmented" v1.1-0 package (Muggeo 2008), with a maximum of 200 iterations and 10 bootstraps. Daily weight changes were calculated as the difference in weight between the first breakpoint and the third breakpoint. We excluded days for which the $r$-squared value of the piecewise regression were less than 0.95 , when it rained based on data from the Australian Bureau of Meteorology, or when we interfered with the hives.

A linear mixed effect model was then used to compare the effects of the treatments on daily weight gains. Treatment, date and their interactions were used as fixed effects. Dates nested within hives were used as random effects and as the autocorrelation structure using the function "corCAR1" from the package "nlme" v3.1-142 (Pinheiro et al. 2019). 


\subsubsection{Temperature regulation}

Bees try to regulate the temperature of the brood to an optimum at $35{ }^{\circ} \mathrm{C}$ (Jones et al. 2004). We compared the temperature regulation efficiency between groups by measuring the average temperature from data collected by the temperature loggers every $30 \mathrm{~min}$. We chose to focus on the overwintering period from the beginning of the treatment on the 10th of April 2019 to the last evaluation on the 20th of August 2019, because of the variation in sample size due to the death of colonies in spring. A linear mixed effect model was used to compare the effect of the treatment and of its interaction with time on the daily average temperature. Treatment, time and their interaction were used as fixed effects, dates nested within hives were used as a random effect and as the autocorrelation structure, using the function "corCAR1".

\subsubsection{Individual foraging performances and survival}

The age at onset of foraging can be detected from daily flight patterns (Colin et al. 2019c). We considered that bees transitioned from performing orientation flights to performing foraging flights on the first day where they performed their first trip less than 5 hours after sunrise and accumulated more than 20 min of flight time in a day. This threshold is not arbitrary and was determined using a linear discriminant analyses with seven different parameters of daily flights. This was shown to accurately classify days of orientation flights and days of foraging flights in over $79 \%$ and $97 \%$ of the cases respectively (Colin et al. 2019c).

The number of individual foraging flights, average flight duration and age at onset of foraging were compared between groups using Dunn's signed rank tests (data were either not normally distributed or heteroscedastic).

Bee survival between groups for bees that performed at least 1 flight and returned to the hive (to exclude bees that could not fly post tagging) was compared using a Cox proportional hazards regression model using "survival" v2.41-3 (Therneau 2015). Survival curves were drawn using the "survminer" v0.4.3 (Kassambara and Kosinski 2018).

\section{RESULTS}

\subsection{Colony productivity}

One hive treated with tau-fluvalinate died during the treatment and was considered dead on the second hive evaluation on the 8th of May 2018. Two hives treated with thymol died over winter and were considered dead on the third hive evaluation on the 20th of August 2018. We were not able to determine a specific cause of death. We did not include these data in the comparisons of bees and brood amounts and food stores. Four other hives were recorded dead or too weak to be kept due to the risk of hive beetle infestations during a routine check on October 25th 2018 about a year after the beginning of the experiments, two in the control group, one in the thymol group and one in the tau-fluvalinate group.

There were no significant differences in number of capped cells, number of adult bees, or mass of food stores between treatments groups in any of the three hive evaluations (Table I) (Figures 1, 2 and 3).

The daily weight gains in colonies treated with thymol differed significantly from the daily weight gains in control colonies and this effect varied with time (thymol: $t=-2.257, \mathrm{df}=17, p=$ 0.038 , interaction thymol/time: $t=2.253$, $\mathrm{df}=$ $710, p=0.025)$. They were lower at the end of the treatment and in the following summer but not during spring (Figure 4). There was no effect of tau-fluvalinate on daily food intake compared to the control group and there was no significant interaction between the tau-fluvalinate treatment and time compared to the control group (taufluvalinate: $t=0.194$, df $=17, p=0.848$, interaction tau-fluvalinate/time: $t=-0.193, \mathrm{df}=710$, $p=0.847$ ) (Figure 4).

\subsection{Colony temperature regulation}

There was no significant effect of the taufluvalinate treatment on the daily average temperature compared to the control group (taufluvalinate vs control: $t=0.860, \mathrm{df}=17, p=$ 0.402, tau-fluvalinate/time: $t=-0.868$, df $=$ 


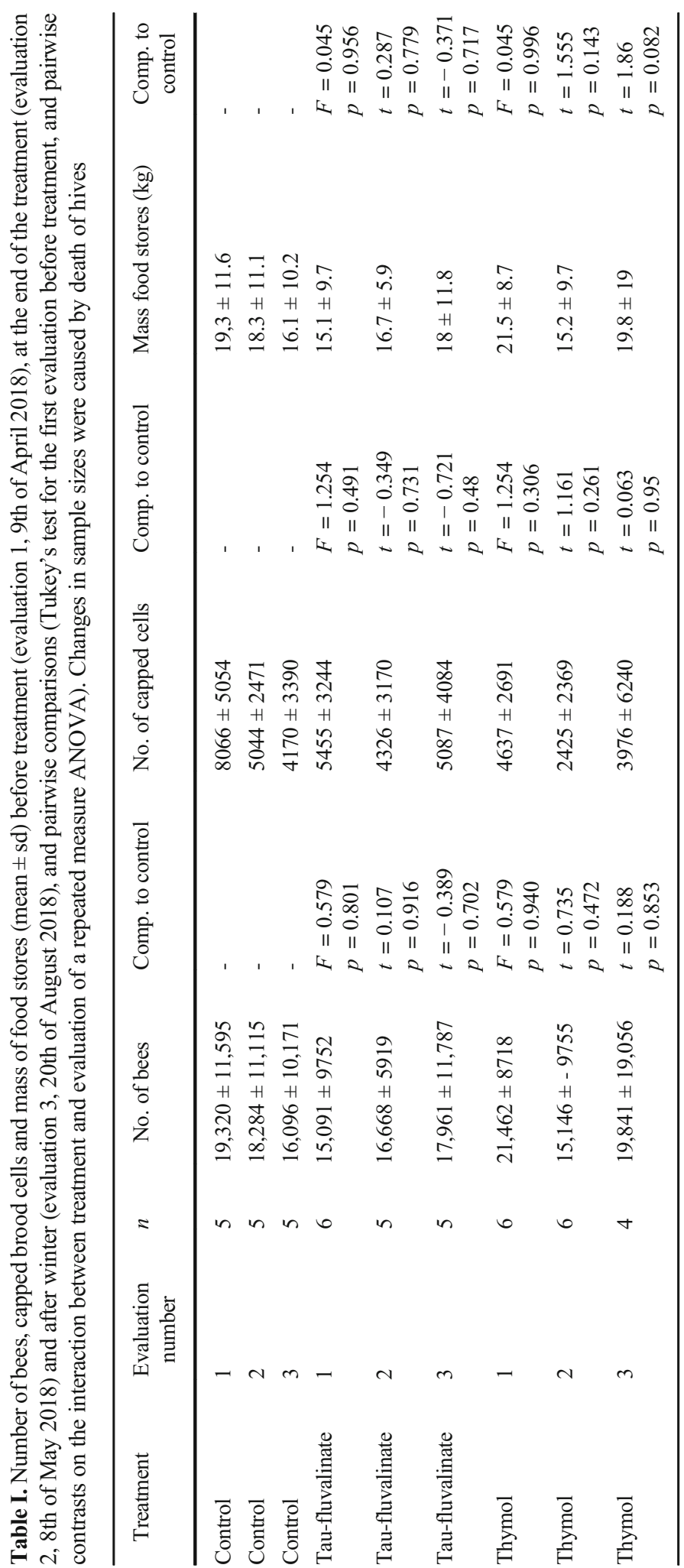




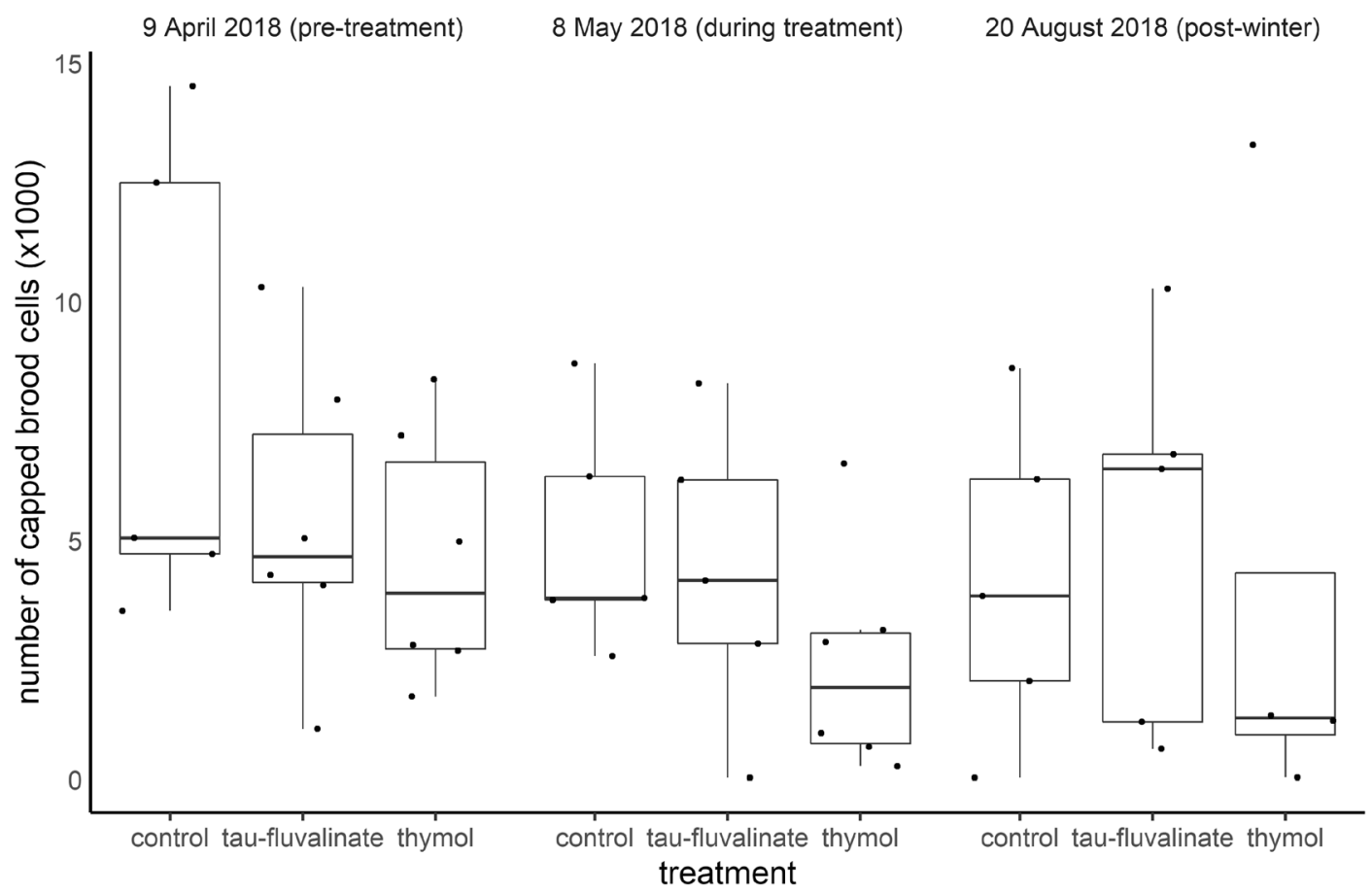

Figure 1. Number of capped brood cells in colonies in the control, tau-fluvalinate, and thymol groups, before treatment (left), at the end of the treatment (centre) and after winter (right). Boxes represent the first and third quartiles and the thick line the median; whiskers extend to $1.5 \times$ the interquartile distance. Individual data points are shown for each hive. There were no significant differences between groups (see Table I).

$2195, p=0.385)$ but the average temperature in the thymol group differed from the temperature in the control group and this difference varied with time (thymol vs control: $t=2.339, \mathrm{df}=17, p=$ 0.032 , thymol/time: $t=-2.359, \mathrm{df}=2195, p=$ 0.018 ) (Figure 5). Data were analysed from the beginning of the treatment on the 10th of April 2018 to the last evaluation on the 20th of August 2018. Data for the whole period are shown in Figure 5, from the beginning of the treatment to the end of the records in January 2019, and illustrate the complexity of analysing time-series data: after colonies have died, group averages and standard deviations change drastically suggesting a strong effect of weak, dying hives on the groups' averages.

\subsection{Individual bee performance assessed with RFID}

For our RFID analyses, we only included tagged bees that completed at least one flight.
For the control groups, this was 168 bees from 299 bees tagged from 6 hives. Tau-fluvalinate: 193 bees from 347 bees tagged from 6 hives (Supplementary Material 4 and 5). Thymol: 137 bees from 287 bees tagged from 5 hives. This rate of loss post tagging is not unusual in RFID studies (Colin et al. 2019c), and is mostly due by the presence of glue on the bees' wings.

\subsubsection{Number of trips}

The number of orientation trips performed by bees that became foragers did not differ significantly between groups (Dunn's test: control vs tau-fluvalinate: $z=0.666, p=0.252$, control vs thymol: $z=0.003, p=0.499$; control group: mean $=17.7 \pm 11.5 \mathrm{sd}$, tau-fluvalinate group: mean $=15.4 \pm 10 \mathrm{sd}$, thymol group: mean = $17.2 \pm 10.7 \mathrm{sd}$ ) (Figure 6).

The number of lifetime foraging trips performed by bees differed between groups, bees in the control group performed significantly fewer 


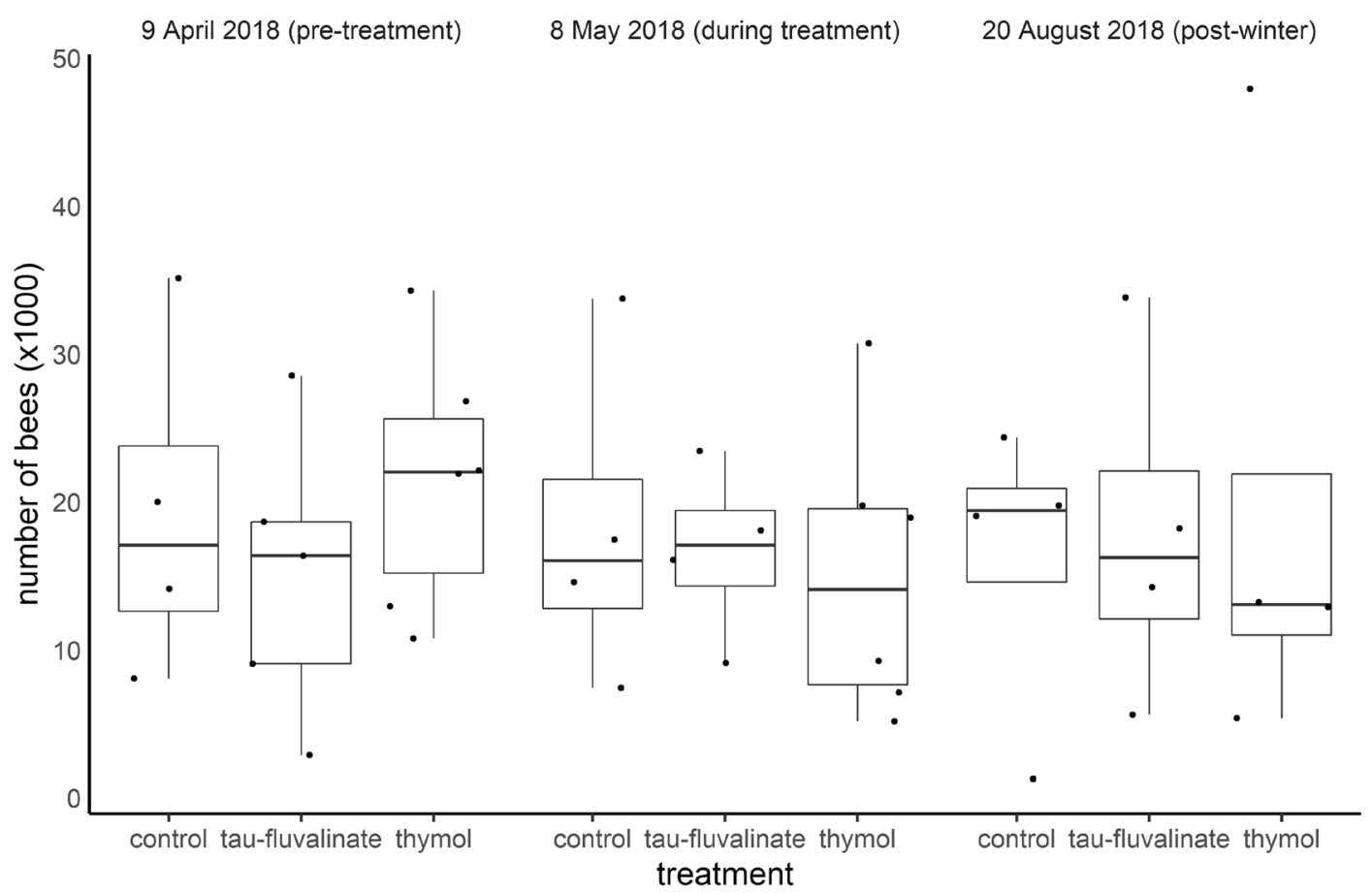

Figure 2. Number of bees in colonies in the control, tau-fluvalinate and thymol groups, before treatment (left), at the end of the treatment (centre) and after winter (right). Boxes represent the first and third quartiles and the thick line the median; whiskers extend to $1.5 \times$ the interquartile distance. Individual data points are shown for each hive. There were no significant differences between groups (see Table I).

foraging trips in their lifetime (mean $=15 \pm 13.7$ sd, Dunn's test: $Z=2.507, p=0.006$ ) than bees in the tau-fluvalinate group $($ mean $=28.9 \pm 25.3 \mathrm{sd}$ ) or bees in the thymol group (mean $=27.6 \pm 25.2$ sd, Dunn's test: $Z=1.831, p=0.034$ ) (Figure 6).

\subsubsection{Average trip duration}

The average orientation trip duration performed by bees that became foragers differed significantly between the control and the tau-fluvalinate groups (Dunn's test: $z=-2.014, p=0.022$ ) but not the control and the thymol groups (Dunn's test: $z=-$ $1.139, p=0.127$ ). Control group bees performed the shortest orientation flights (control group: mean = $5.38 \mathrm{~min} \pm 4.18 \mathrm{sd}$, tau-fluvalinate group: mean $=$ $9.78 \mathrm{~min} \pm 12.6 \mathrm{sd}$, thymol group: mean $=8.01 \mathrm{~min}$ $\pm 7 \mathrm{sd}$ ) (Figure 7).

The average duration of foraging trips differed significantly between groups. The control and taufluvalinate groups differed (Dunn's test: $z=1.67$, $p=0.048)$, but the control and thymol groups did not (Dunn's test: $z=-0.084, p=0.467$ ) (control group: mean $=29.3 \mathrm{~min} \pm 25.3 \mathrm{sd}$, tau-fluvalinate group: mean $=19.1 \mathrm{~min} \pm 10.9 \mathrm{sd}$, thymol group: mean $=30.3 \min \pm 31.3 \mathrm{sd}$ ) (Figure 7$)$.

\subsubsection{Age at first foraging}

The age at onset of foraging differed significantly between the control and tau-fluvalinate groups differed (Dunn's test: $z=2.003, p=$ 0.023 ) but the control and thymol groups did not (Dunn's test: $z=0.958, p=0.169$ ) (control group: mean $=29.5 \pm 13.7 \mathrm{sd}$, tau-fluvalinate group: mean $=24.8 \pm 11.8 \mathrm{sd}$, thymol group: mean $=26.4 \pm 9.68 \mathrm{sd})($ Figure 8$)$.

\subsubsection{Survival analysis}

Mortality rate was not significantly different between the control group and the tau-fluvalinate 


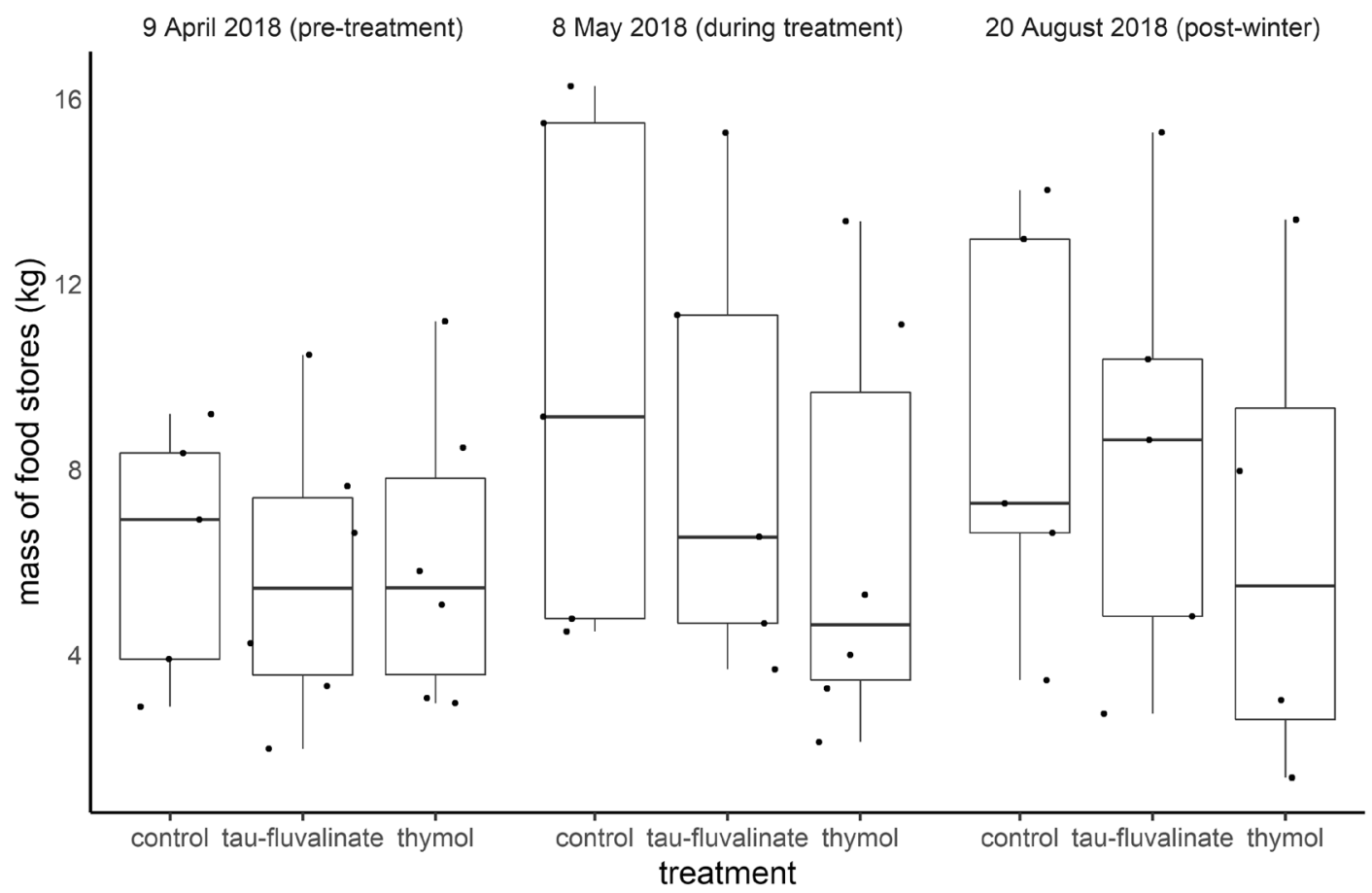

Figure 3. Mass of food stores from colonies in the control, tau-fluvalinate, and thymol groups, before treatment (left), at the end of the treatment (centre) and after winter (right). Boxes represent the first and third quartiles and the thick line the median; whiskers extend to $1.5 \times$ the interquartile distance. Individual data points are shown for each hive. There were no significant differences between groups (see Table I).

group (Cox Proportional Hazards Model, $z=$ $0.532, p=0.595$ ) or between the control group and the thymol group (Cox Proportional Hazards Model, $z=1.251, p=0.211)$. The average age at death was highest for the control group (18.7 days $\pm 13.3 \mathrm{sd}, n=138$ ), then the tau-fluvalinate group (17 days $\pm 12 \mathrm{sd}, n=138$ ) and finally the thymol group (14.7 days $\pm 11.2 \mathrm{sd}, n=119$ ) (Figure 9).

\section{DISCUSSION}

Here we explored the effects of autumn treatments of two of the most commonly used commercial miticides (thymol and tau-fluvalinate) on colony productivity and survival, and the behaviour of individual forager bees. In considering these results, we emphasise that our study was performed over autumn and winter in Sydney, where winters are mild with only a few days below freezing and where $V$. destructor was not present.
Although the effects of miticides on individual honey bees have been extensively studied (Tihelka 2018), little data are available on the impact on the performance of whole bee colonies (Colin et al. 2019b; Odemer and Rosenkranz 2018). Colony-level data are essential to take into account the capacity for buffering or amplification of individual effects that can arise through social interactions in honey bee colonies (Straub et al. 2015; Barron 2015; Perry et al. 2015). Conclusions of relevance to beekeepers can only be reached by performing experiments on full colonies (Straub et al. 2015). Behavioural experiments at the individual level can help identify mechanisms responsible for colony-level changes, or reveal effects buffered by the colony. We stress the importance of increasing the proportion of colony-level to individual-level experiments to assess how miticides might best be used in the apiary. 


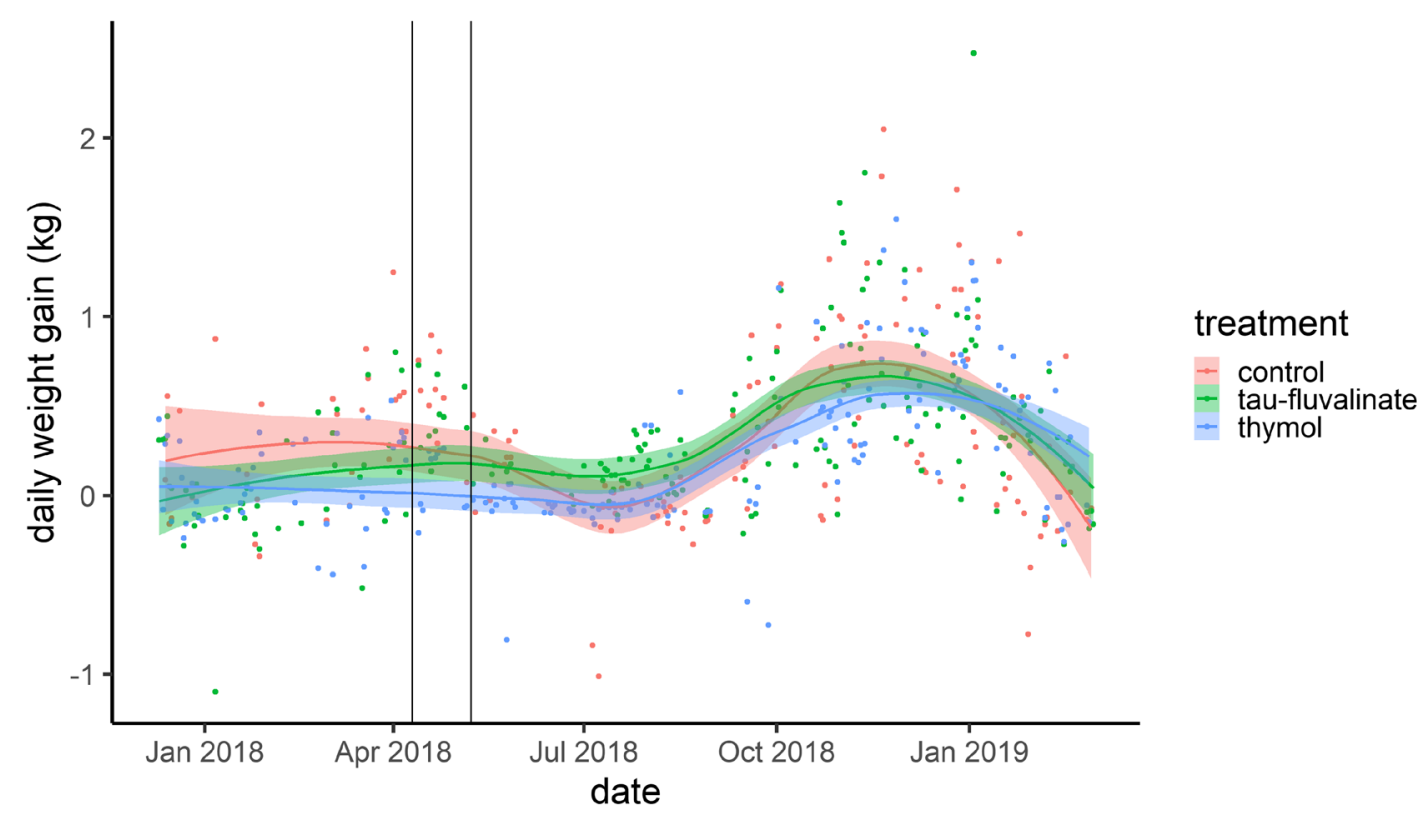

Figure 4. Daily weight changes measured as the weight of the hive at the end of the day when foraging activity stopped minus the weight of the hive before workers depart in the morning of the same day. Extreme negative values are likely due to animals interfering with the recording equipment in the morning (for example, birds landing on hives during measurements) or days of extreme heat when food is scarce and water evaporates rapidly. Vertical lines represent the beginning and end of the treatment. Lines represent a Loess regression. Hives in the thymol treatment group accumulated significantly less mass than hives in the control group (see section "Colony productivity" of the Results).

Colonies were assessed from April to August: a five-month period from late autumn to the end of winter in Sydney, Australia. Our results show no adverse effects of either of these miticide treatments on brood and bee numbers or amount of food stores over winter (Figures 1, 2 and 3, Table I). However, the temperatures within the colonies treated with thymol were on average lower overwinter than control colonies (Figure 5). Colony temperature regulation in bee colonies is essential for the brood development (Jones and Oldroyd 2006). Variations in brood amounts can be responsible for changes in temperature regulation performances (Meikle et al. 2016b). Although we observed no significant differences in brood amounts between treatment groups throughout the experiment, the thymol group had lower brood amounts in the first evaluation following treatment, which was the period over which we analysed the temperature data. This might have contributed to a reduction of the average temperature over winter in the thymol group. Summer thymol treatment was not found to significantly reduce average temperature overwinter but affected brood amounts in bee colonies temporarily (Colin et al. 2019b; Colin et al. 2019a). Summer thymol treatment is not associated with increased over winter mortality, unlike late thymol application which was previously associated with higher winter mortality (Beyer et al. 2018). An effect of thymol on brood amounts shortly before winter may not leave enough time for the hives to recover, which could explain lower average temperatures during winter. It is nonetheless reassuring that we documented no strong adverse effects of either miticide treatments on bee and brood populations during this period in Sydney, but late thymol treatment should be treated with caution before more data become available.

A previous study also reported no adverse effects of tau-fluvalinate on bees (Odemer and 


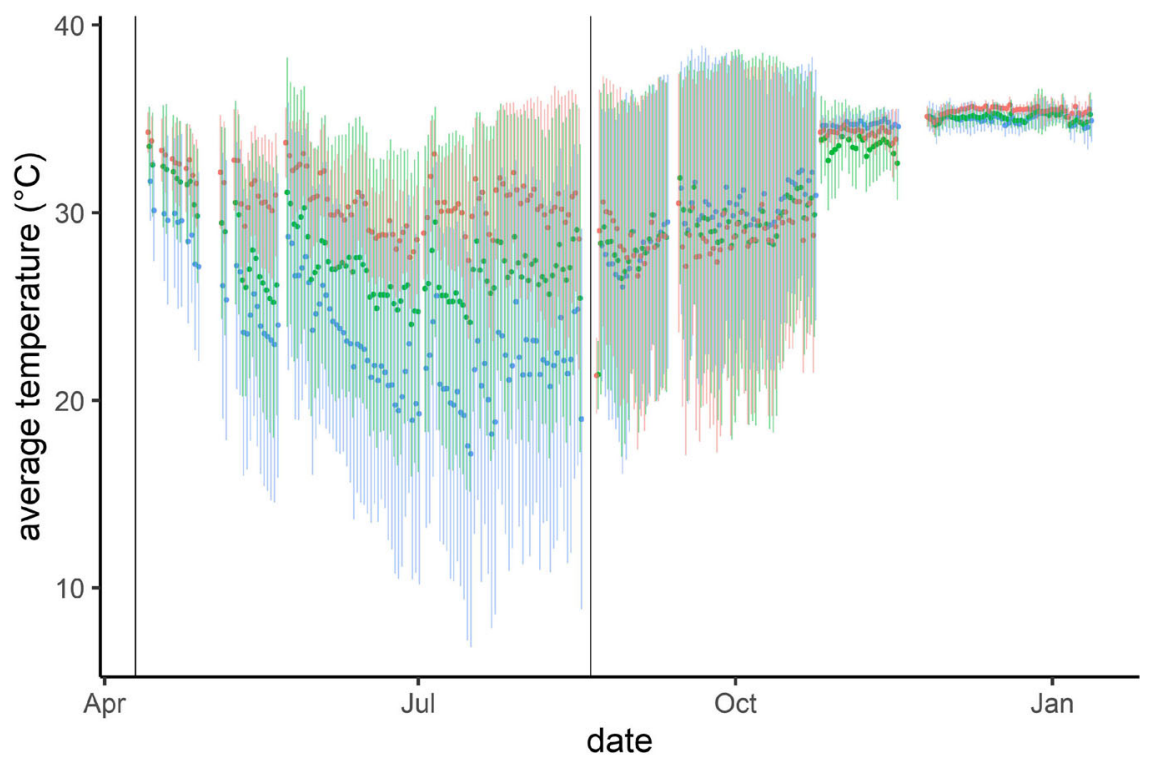

treatment

control

- tau-fluvalinate

thymol

Figure 5. Average temperature $\left({ }^{\circ} \mathrm{C}\right)$ measured every $30 \mathrm{~min}$ within the brood nest \pm standard deviation. Results in the text refer to the period between the beginning of the treatment on the 10th of April 2018 (first vertical line) and the last colony evaluation at the end of the winter on the 20th of August 2018 (second vertical line). After this period, dead hives or hives that were too weak to remain in the experiment were removed (two hives on the 20th of August, four hives on the 25th of October). Every 50 days, loggers had to be collected to download the data and reset the memory. There was no temperature recording during this operation. Days where colonies were inspected were also removed. Colonies treated with thymol were significantly colder in winter (see section "Colony temperature regulation" of the Results).

Rosenkranz 2020), although these colonies did not perform better than control colonies in the presence of $V$. destructor . Our findings contrast with another study that reported some adverse effects of a thymol treatment on bee and brood population and food stores and no effects on temperature regulation (Colin et al. 2019b), but thymol was applied in summer. This perhaps suggests that late autumn treatments could benefit bee colonies more by having fewer adverse effects on bees, as long as their efficiency at controlling $V$. destructor remains the same as for spring or summer treatments.

We measured the effect of miticide exposure during development on the behaviour and performance of individual bees. The survival of the control bees was longer than that of summer bees estimated in the same conditions (Colin et al. 2019c), but lower than that of data from the longevity of winter bees from the literature (up to 252 days in winter in Japan, Fukuda and Sekiguchi 1966). This could be due bees continuing to forage and rear brood during the mild winter of the Sydney region, as longevity is thought to be affected by foraging and brood rearing activity (Kunert and Crailsheim 1988). Unsurprisingly, bees involved in this winter experiment started foraging later (29.5 days old in the control group) and performed fewer trips on average (15 in lifetime in the control group) than previously reported for summer bees in the literature (Colin et al. 2019c; Perry et al. 2015; Søvik et al. 2015; He et al. 2013; Prado et al. 2019; Bordier et al. 2018), probably because the weather limited the number of days they could perform flights. Average trip durations (29.3 min in the control group) fell well within the ranges previously reported during the literature (Colin et al. 2019c; Perry et al. 2015; Søvik et al. 2015; He et al. 2013; Prado et al. 2019; Bordier et al. 2018), suggesting winter foraging did not affect foraging distance.

Regarding the effects of the treatments, we found no individual effects of the autumn thymol 

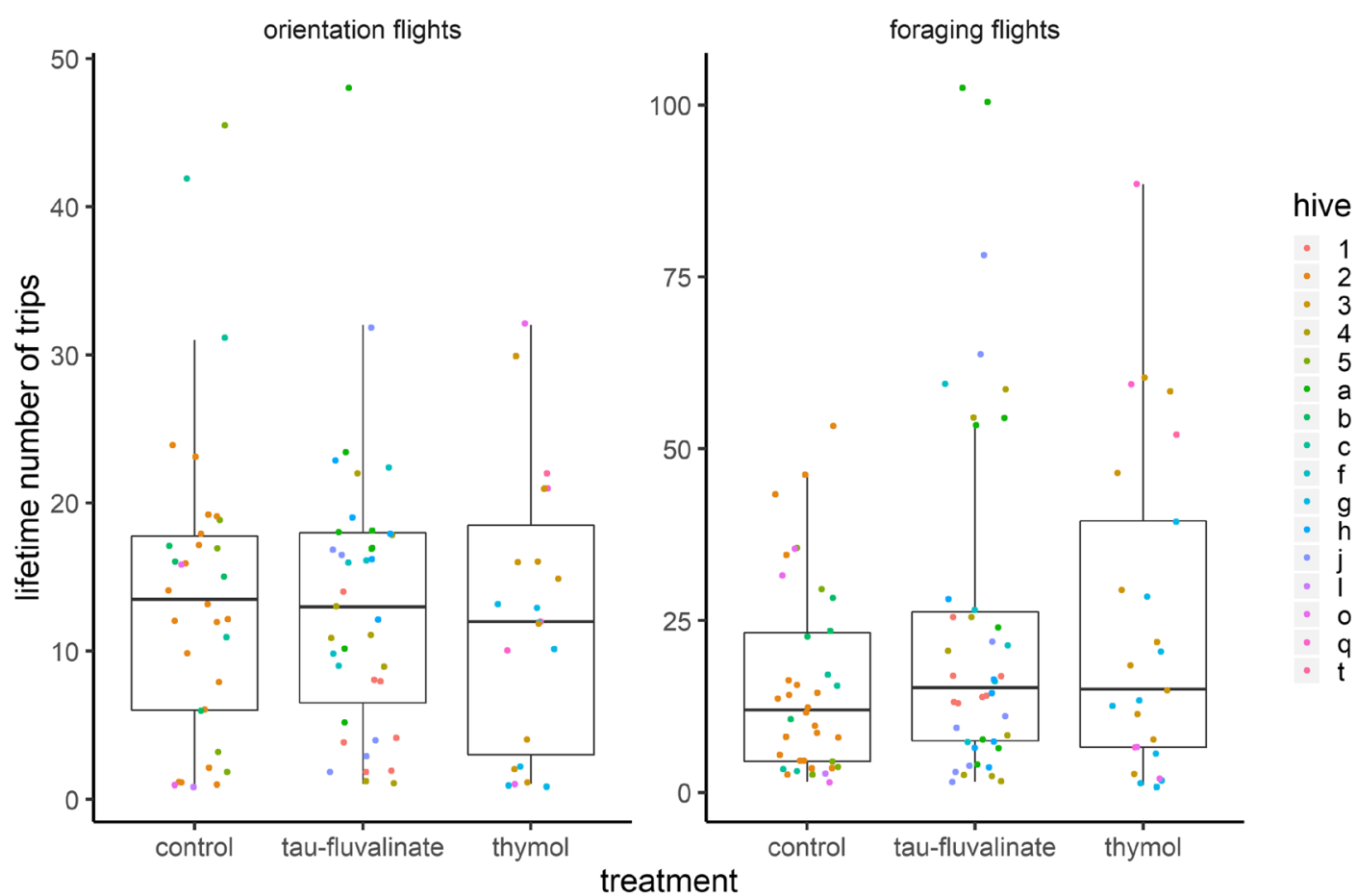

Figure 6. Lifetime number of trips of individual bees in the two treatment groups and controls. Points indicate individual bees. Colours identify individual hives (control hives: 2, 5, b, c, 1, o; tau-fluvalinate hives: 1, 4, a, f, h, j; thymol hives: $3, \mathrm{~g}, \mathrm{I}, \mathrm{q}, \mathrm{t}$ ). Boxes represent the first and third quartiles, the thick line the median, whiskers extend to $1.5 \times$ the interquartile distance. There were no differences in the number of orientation trips (left) performed by the bees of the different treatment groups and controls, but bees in the control group performed fewer foraging flights (right) on average than bees in the tau-fluvalinate or thymol groups (see section "Individual bee performance assessed with RFID" of the Results).

treatment on the age at onset of foraging, average trip duration, and mortality compared to the control group (Figures 6, 7, 8 and 9). This is consistent with our results on colony-level performances. Bees exposed to thymol were found to perform more lifetime foraging trips than bees in the control group (Figure 6). Bees from the autumn tau-fluvalinate treatment foraged earlier in life and performed more foraging trips but these trips were also shorter than those performed by bees in the control group (Figures 6 and 7). These changes in foraging behaviour with taufluvalinate treatment did not cause any detectable changes in colony population or performance (Figures 1, 2, 3, 4 and 5).

The effects of pesticides on the ontogeny and traits of life history of foraging honey bees are known to be complex (Prado et al. 2019; Colin et al. 2019c). In late autumn, longer-lived workers called "winter bees" are raised and have an average longevity of over three months (Fukuda and Sekiguchi 1966). These longer-lived bees ensure that the winter population of the hive remains sufficient to maintain the temperature of the colony above freezing, which enables the survival of the queen and colony over winter (Jones and Oldroyd 2006). Our data suggest that bees exposed to tau-fluvalinate before winter could have higher chances of increased mortality because they were stimulated both to start foraging at a younger age and performed more trips than the winter bees in the control group. Similarly, thymol caused an increase in the number of foraging trips performed by bees in late autumn. For a colony heading into winter, it may not be advantageous to expend bees in foraging. 


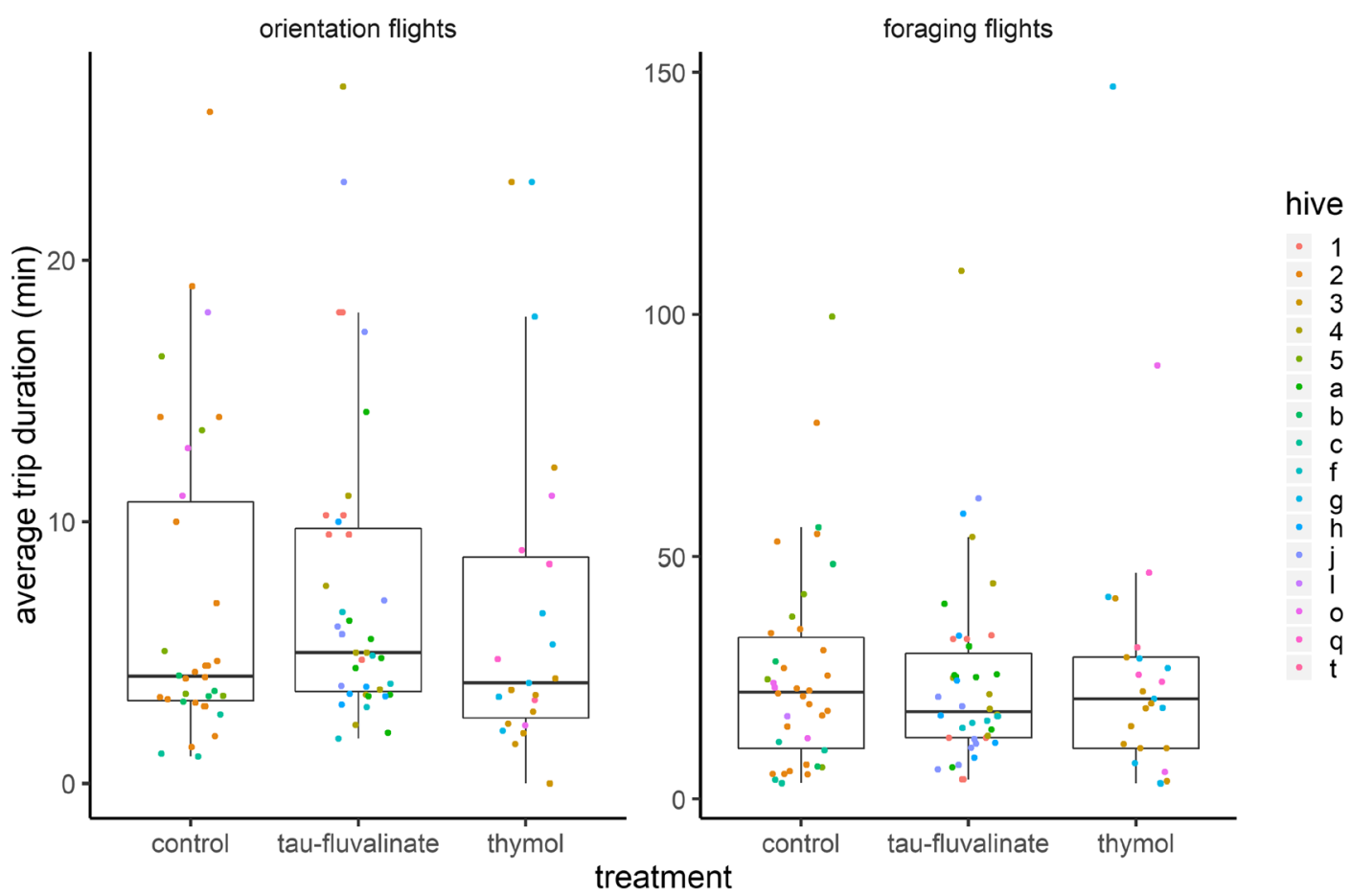

Figure 7. Average trip duration of bees in the two treatment groups and controls. Points indicate individual bees coloured by hive. There were no differences in trip duration in orientation flights (left), and no difference in foraging trip duration between thymol treated bees and controls, but bees in the tau-fluvalinate group performed significantly shorter foraging trips (right) (see section "Individual bee performance assessed with RFID" of the Results).

Overall, however, it is reassuring that any impacts of autumn miticide treatments on bee behaviour and colony performance were minor. Bee colonies can buffer such effects to a certain degree and limit their consequences on the survival of the colonies (Henry et al. 2015). Effects of miticides on mite infestation levels may also compensate for any negative effects on the bees themselves (Colin et al. 2019b).

We caution, however, that long-term reliance on chemical miticides to control $V$. destructor is not ideal. Miticide residues accumulate in bee products such as stored pollen, wax and honey-including that harvested for human alimentation (Calatayud-
Vernich et al. 2018; Mullin et al. 2010). Given the risks of accumulation of pesticides in honey and wax and synergistic effects of these contaminants with miticides to impact bees, we recommend more research into the development of non-chemical alternatives for $V$. destructor control. These will also reduce the risks of Varroa population rapidly developing resistance to miticides (Dietemann et al. 2012; Milani 1999). Wide-scale studies of the comparative benefits of different miticide treatments under different climates, and with different $V$. destructor infestation levels could help provide regional and situation-relevant advice to beekeepers. 


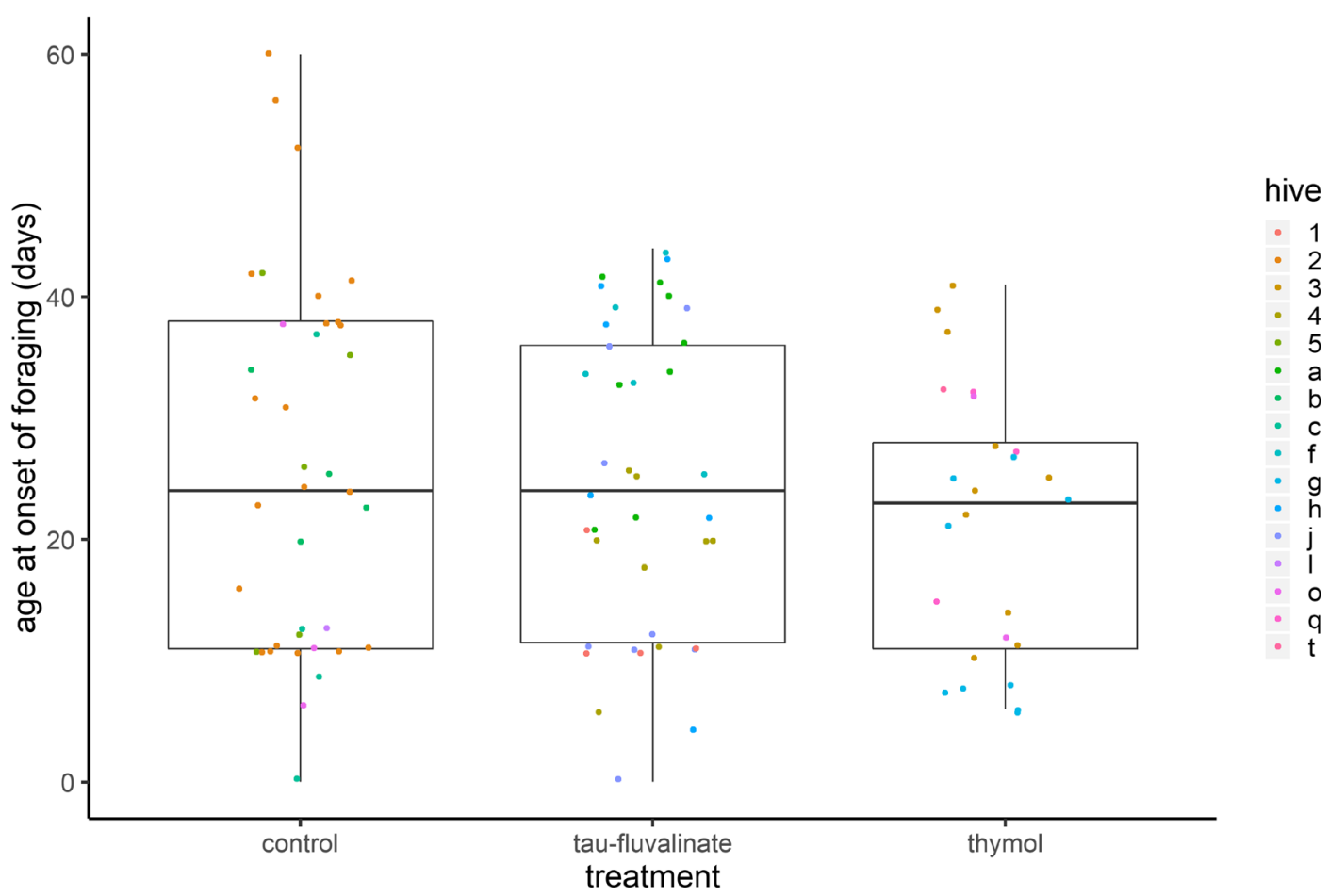

Figure 8. Age at onset of foraging of individual bees in the control, tau-fluvalinate, and thymol groups. The onset of foraging was calculated as the first day where an individual bee performed her first trip less than five hours after sunrise and accumulated more than 20 min of flight. Points indicate individual bees coloured by hive. Boxes represent the first and third quartiles and the thick line the median; whiskers extend to $1.5 \times$ the interquartile distance. Bees in the tau-fluvalinate group started foraging four days earlier on average. There were no differences between bees in the control and bees in the thymol group (see section "individual bee performance assessed with RFID" of the Results). 


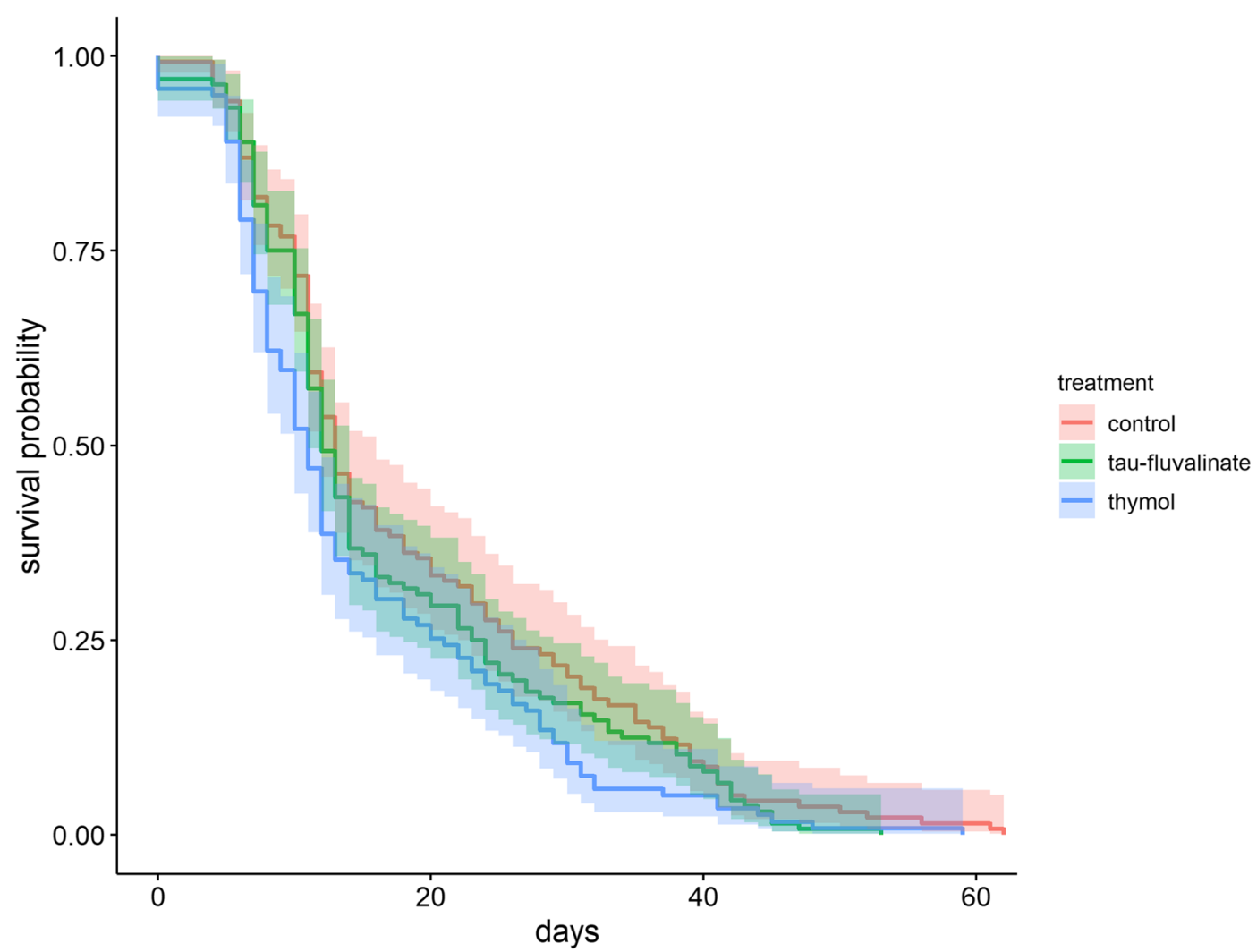

Figure 9. Survival probability of individual bees in the control, tau-fluvalinate, and thymol groups. Survival curves were obtained using the "surv_fit" function of the package "survminer" (see Methods), without specifying clusters (methods are currently lacking for such fits). There were no significant differences in survival between the control and the treatment groups (see section "Individual bee performance assessed with RFID" of the Results). 


\section{SUPPLEMENTARY INFORMATION}

The online version contains supplementary material available at https://doi.org/10.1007 /s13592-020-00837-3.

\section{ACKNOWLEDGEMENTS}

We thank Shaun Garvey for his help with hive maintenance.

\section{AUTHOR CONTRIBUTIONS}

Designed study: TC, ABB, WGM. Gathered data: TC, JW, CF, XW. Analysed data: TC. Wrote manuscript: TC, ABB. Developed manuscript: all authors.

\section{FUNDING}

TC received an iMQRES scholarship from Macquarie University. ABB is funded by the Australian Research Council (ARC Future Fellowship no. 140100452) and by the Lord Mayor's Charitable Foundation through the Eldon \& Anne Foot Trust. ABB and WGM are funded by the United States Department of Agriculture ARS agreement no: 58-5342-3-004F.

\section{DATA AVAILABILITY}

All data generated or analysed during this study are included in this published article (and its supplementary information files).

Effets des traitements miticides tardifs sur le butinage et la productivité des colonies d'abeilles européennes (Apis mellifera).

miticides / acaricides / Varroa destructor / RFID / mesure du poids en continu.

Auswirkungen einer späten Akarizidbehandlung auf die Sammelaktivität und Produktivität europäischer Honigbienen (Apis mellifera).

Milbenbehandlung / Akarizide / Varroa destructor / RFID / kontinuierliche Gewichtsmessung.

\section{REFERENCES}

Adamczyk S., Lázaro R., Pérez-Arquillué C., Conchello P., Herrera A. (2005) Evaluation of residues of essential oil components in honey after different anti-Varroa treatments. J. Agric. Food Chem. 53, 10085-10090.

Alayrangues J., Hotier L., Massou I., Bertrand Y., Armengaud C. (2016) Prolonged effects of in-hive monoterpenoids on the honey bee Apis mellifera. Ecotoxicology 25, 856-862.

Alburaki M., Steckel S. J., Chen D., McDermott E., Weiss M., Skinner J. A., Kelly H., et al. (2017) Landscape and pesticide effects on honey bees: forager survival and expression of acetylcholinesterase and brain oxidative genes. Apidologie 48, 556-571.

Barron A. B. (2015) Death of the bee hive: understanding the failure of an insect society. Curr. Opin. Insect Sci. 10, 45-50.

Berry J. A., Hood W. M., Pietravalle S., Delaplane K. S. (2013) Field-Level Sublethal Effects of Approved Bee Hive Chemicals on Honey Bees (Apis mellifera L). PLoS One 8.

Beyer M., Junk J., Eickermann M., Clermont A., Kraus F., Georges C., Reichart A., Hoffmann L. (2018) Winter honey bee colony losses, Varroa destructor control strategies, and the role of weather conditions: Results from a survey among beekeepers. Res. Vet. Sci. 118, $52-60$.

Boncristiani H., Underwood R., Schwarz R., Evans J. D., Pettis J., Vanengelsdorp D. (2012) Direct effect of acaricides on pathogen loads and gene expression levels in honey bees Apis mellifera. J. Insect Physiol. 58, 613-620.

Bonnafé E., Alayrangues J., Hotier L., Massou I., Renom A., Souesme G., Marty P., Allaoua M., Treilhou M., Armengaud C. (2017) Monoterpenoid-based preparations in beehives affect learning, memory, and gene expression in the bee brain. Environ. Toxicol. Chem. 36, 337-345.

Bordier C., Conte Y. Le, Klein S., Alaux C., Barron A. B. (2018) Stress decreases pollen foraging performance in honeybees. J. Exp. Biol. 221 , jeb171470.

Brodschneider R., Brus J., Danihlík J. (2019) Comparison of apiculture and winter mortality of honey bee colonies (Apis mellifera) in Austria and Czechia. Agric. Ecosyst. Environ. 274, 24-32.

Burley L. M., Fell R. D., Saacke R. G. (2008) Survival of Honey Bee (Hymenoptera: Apidae) Spermatozoa Incubated at Room Temperature from Drones Exposed to Miticides. J. Econ. Entomol. 101, 1081-1087.

Calatayud-Vernich P., Calatayud F., Simó E., Picó Y. (2018) Pesticide residues in honey bees, pollen and beeswax: Assessing beehive exposure. Environ. Pollut. 241, 106-114.

Carayon J. L., Téné N., Bonnafé E., Alayrangues J., Hotier L., Armengaud C., Treilhou M. (2014) Thymol as an alternative to pesticides: Persistence and effects of Apilife Var on the phototactic behavior of the 
honeybee Apis mellifera. Environ. Sci. Pollut. Res. 21, 4934-4939.

Carroll M. J., Meikle W. G., McFrederick Q. S., Rothman J. A., Brown N., Weiss M., Ruetz Z., Chang E. (2018) Pre-almond supplemental forage improves colony survival and alters queen pheromone signaling in overwintering honey bee colonies. Apidologie 49, $827-837$.

Coffey M. F., Breen J. (2016) The efficacy and tolerability of Api-Bioxal as a winter varroacide in a cool temperate climate climate. J. Apic. Res. 8839, 1-9.

Colin T., Bruce J., Meikle W. G., Barron A. B. (2018) The development of honey bee colonies assessed using a new semi-automated brood counting method: Combcount. PLoS One 13, 1-14.

Colin T., Lim M. Y., Quarrell S. R., Allen G. R., Barron A. B. (2019a) Effects of thymol on European honey bee hygienic behaviour. Apidologie 50, 141-152.

Colin T., Meikle W. G., Paten A. M., Barron A. B. (2019b) Long-term dynamics of honey bee colonies following exposure to chemical stress. Sci. Total Environ. 677, 660-670.

Colin T., Meikle W. G., Wu X., Barron A. B. (2019c) Traces of a Neonicotinoid Induce Precocious Foraging and Reduce Foraging Performance in Honey Bees. Environ. Sci. Technol. 53, 8252-8261.

Colin T., Plath J. A., Klein S., Vine P., Devaud J.-M., Lihoreau M., Meikle W. G., Barron A. B. (2020) The miticide thymol in combination with trace levels of the neonicotinoid imidacloprid reduces visual learning performance in honey bees (Apis mellifera). Apidologie, 1-11.

Dietemann V., Pflugfelder J., Anderson D., Charrière J.-D., Chejanovsky N., Dainat B., Miranda J. de, et al. (2012) Varroa destructor : research avenues towards sustainable control. J. Apic. Res. 51, 125-132.

Frost E. H., Shutler D., Hillier N. K. (2013) Effects of fluvalinate on honey bee learning, memory, responsiveness to sucrose, and survival. J. Exp. Biol. 216, 2931-8.

Fukuda H., Sekiguchi K. (1966) Seasonal change of the honeybee worker longevity in Sapporo, North Japan, with notes on some factors affecting the life-span. Japanese J. Ecol. 16, 206-212.

Giusti M., Sabelli C., Donato A. Di, Lamberti D., Paturzo C. E., Polignano V., Lazzari R., Felicioli A. (2017) Efficacy and safety of Varterminator, a new formic acid medicine against the varroa mite. J. Apic. Res. 56, 162-167.

Gregorc A., Evans J. D., Scharf M., Ellis J. D. (2012) Gene expression in honey bee (Apis mellifera) larvae exposed to pesticides and Varroa mites (Varroa destructor). J. Insect Physiol. 58, 1042-1049.

Haarmann T., Spivak M., Weaver D., Weaver B., Glenn T. (2002) Effects of Fluvalinate and Coumaphos on Queen Honey Bees (Hymenoptera: Apidae) in Two Commercial Queen Rearing Operations. J. Econ. Entomol. 95, 28-35.
Hatjina F., Haristos L. (2005) Indirect effects of oxalic acid administered by trickling method on honey bee brood. J. Apic. Res. 44, 172-174.

He X., Wang W., Qin Q., Zeng Z., Zhang S., Barron A. B. (2013) Assessment of flight activity and homing ability in Asian and European honey bee species, Apis cerana and Apis mellifera, measured with radio frequency tags. Apidologie 44, 38-51.

Henry M., Cerrutti N., Aupinel P., Decourtye A., Gayrard M., Odoux J.-F., Pissard A., Rüger C., Bretagnolle V. (2015) Reconciling laboratory and field assessments of neonicotinoid toxicity to honeybees. Proc. R. Soc. B Biol. Sci. 282, 20152110.

Holst N., Meikle W. (2018) Breakfast Canyon Discovered in Honeybee Hive Weight Curves. Insects 9, 176.

Johnson R. M., Dahlgren L., Siegfried B. D., Ellis M. D. (2013) Acaricide, fungicide and drug interactions in honey bees (Apis mellifera). PLoS One 8, e54092.

Jones J. C., Myerscough M. R., Graham S., Oldroyd B. P. (2004) Honey bee nest thermoregulation: diversity promotes stability. Science $\mathbf{3 0 5}, 402-4$.

Jones J. C., Oldroyd B. P. (2006) Nest Thermoregulation in Social Insects .

Jong D. De, Morse R. A., Eickwort G. C. (1982) Mite pests of honey bees. Annu. Rev. Entomol. 27, 229-252.

Kasiotis K. M., Tzouganaki Z. D., Machera K. (2018) Chromatographic determination of monoterpenes and other acaricides in honeybees: Prevalence and possible synergies. Sci. Total Environ. 625, 96-105.

Kassambara A., Kosinski M. (2018) survminer: Drawing Survival Curves using "ggplot2".

Klein S., Cabirol A., Devaud J. M., Barron A. B., Lihoreau M. (2017) Why bees are so vulnerable to environmental stressors. Trends Ecol. Evol. 32, 268-278.

Kunert K., Crailsheim K. (1988) Seasonal changes in carbohydrate, lipid and protein content in emerging worker honeybees and their mortality. J. Apic. Res. 27, 13-21.

Lenth R., Singmann H., Love J., Buerkner P., Herve M. (2018) Package "emmeans."

Martel A. C., Zeggane S. (2002) Determination of acaricides in honey by high-performance liquid chromatography with photodiode array detection. J. Chromatogr. A 954, 173-180.

Meikle W. G., Adamczyk J. J., Weiss M., Gregorc A., Johnson D. R., Stewart S. D., Zawislak J., Carroll M. J., Lorenz G. M. (2016a) Sublethal Effects of Imidacloprid on Honey Bee Colony Growth and Activity at Three Sites in the U.S. PLoS One 11, e0168603.

Meikle W. G., Corby-Harris V., Carroll M. J., Weiss M., Snyder L. A., Meador C. A. D., Beren E., Brown N. (2019) Exposure to sublethal concentrations of methoxyfenozide disrupts honey bee colony activity and thermoregulation. PLoS One 14, 1-21.

Meikle W. G., Holst N., Colin T., Weiss M., Carroll M. J., McFrederick Q. S., Barron A. B. (2018) Using withinday hive weight changes to measure environmental 
effects on honey bee colonies. PLoS One $\mathbf{1 3}$, e0197589.

Meikle W. G., Weiss M. (2017) Monitoring Colony-level Effects of Sublethal Pesticide Exposure on Honey Bees. J. Vis. Exp. 129, 1-10.

Meikle W. G., Weiss M., Beren E. (2020) Landscape factors influencing honey bee colony behavior in Southern California commercial apiaries. Sci. Rep. 10, $1-16$.

Meikle W. G., Weiss M., Stilwell A. R. (2016b) Monitoring colony phenology using within-day variability in continuous weight and temperature of honey bee hives. Apidologie 47, 1-14.

Milani N. (1999) The resistance of Varroa jacobsoni Oud. to acaricides. Apidologie 30, 229-234.

Muggeo V. R. M. (2008) segmented: An R Package to Fit Regression Models with Broken-Line Relationships .

Mullin C. A., Frazier M., Frazier J. L., Ashcraft S., Simonds R., vanEngelsdorp D., Pettis J. S. (2010) High Levels of Miticides and Agrochemicals in North American Apiaries: Implications for Honey Bee Health. PLoS One 5.

Odemer R., Rosenkranz P. (2018) Chronic exposure to a neonicotinoid pesticide and a synthetic pyrethroid in full-sized honey bee colonies. bioRxiv, 293167.

Odemer R., Rosenkranz P. (2020) Chronic exposure to a neonicotinoid pesticide and a synthetic pyrethroid in full-sized honey bee colonies. J. Apic. Res. 59, 2-11.

Perry C. J., Søvik E., Myerscough M. R., Barron A. B. (2015) Rapid behavioral maturation accelerates failure of stressed honey bee colonies. Proc. Natl. Acad. Sci. $112,3427-3432$.

Pettis J. S., Collins A. M., Wilbanks R., Feldlaufer M. F. (2004) Effects of coumaphos on queen rearing in the honey bee, Apis mellifera. Apidologie 35, 605-610.

Pinheiro J., Bates D., DebRoy S., Sarkar D. (2019) nlme: Linear and Nonlinear Mixed Effects Models.

Prado A., Pioz M., Vidau C., Requier F., Jury M., Crauser D., Brunet J. L., Conte Y. Le, Alaux C. (2019) Exposure to pollen-bound pesticide mixtures induces longer-lived but less efficient honey bees. Sci. Total Environ. 650 , 1250-1260.

R Core Team R. (2018) R: A language and environment for statistical computing. $R$ Foundation for Statistical Computing. Vienna, Austria.

Rosenkranz P., Aumeier P., Ziegelmann B. (2010) Biology and control of Varroa destructor. J. Invertebr. Pathol. 103, S96-S119.

Serra Bonvehí J., Ventura Coll F., Ruiz Martínez J. A. (2016) Residues of essential oils in honey after treatments to control Varroa destructor. J. Essent. Oil Res. 28, 22-28.

Søvik E., Perry C. J., LaMora A., Barron A. B., Ben-Shahar Y. (2015) Negative impact of manganese on honeybee foraging. Biol. Lett. 11, 1-4.

Straub L., Williams G. R., Pettis J., Fries I., Neumann P. (2015) ScienceDirect Superorganism resilience : eusociality and susceptibility of ecosystem service providing insects to stressors. Curr. Opin. Insect Sci. 12, 109-112.

Therneau T. M. (2015) A Package for Survival Analysis in $S$.

Tihelka E. (2018) Effects of synthetic and organic acaricides on honey bee health: A review. Slov. Vet. Res. 55, 114-140.

Toomemaa K., Martin A., Williams I. H. (2010) The effect of different concentrations of oxalic acid in aqueous and sucrose solution on Varroa mites and honey bees. Apidologie 41, 643-653.

Tsigouri A. D., Menkissoglu-Spiroudi U., Thrasyvoulou A. (2001) Study of tau-fluvalinate persistence in honey. Pest Manag. Sci. 57, 467-471.

Underwood R. M., Traver B. E., López-Uribe M. M. (2019) Beekeeping Management Practices Are Associated with Operation Size and Beekeepers' Philosophy towards in-Hive Chemicals. Insects 10, 10.

Publisher's note Springer Nature remains neutral with regard to jurisdictional claims in published maps and institutional affiliations. 